\title{
A autotipia e as capas da Revista de Pernambuco
}

\author{
The autotypia and the Revista de Pernambuco' covers
}

\author{
MARIZ, Leopoldina; Mestranda; UFPE \\ leomariz@hotmail.com \\ WAECHTER, Hans; PhD; UFPE \\ hnwaechter@terra.com.br
}

\section{Resumo}

Este artigo apresenta parte de uma pesquisa sobre as capas da Revista de Pernambuco publicadas entre os anos de 1924 a 1926. No estudo de artefatos de memória gráfica é importante levar em conta e conhecer bem a tecnologia disponível à época em que estes foram produzidos. A tecnologia pode impor limites ao desenvolvimento de um trabalho gráfico, mas pode também ampliar suas possibilidades. Neste sentido, este artigo pretende investigar a tecnologia usada na impressão das capas da Revista de Pernambuco (1924-1926) relacionando-a às práticas gráficas vigentes naquela época. Assim, descreve não apenas o cenário da indústria gráfica pernambucana, mas também as tecnologias de impressão usadas no início de século XX. Através do conhecimento da produção destes artefatos, esse artigo busca contribuir para um melhor entendimento da prática gráfica no estado de Pernambuco naquele período.

Palavras Chave: memória gráfica, tecnologia de impressão, autotipia.

\begin{abstract}
This article presents part of a research about the Revista de Pernambuco's covers published between the years of 1924 to 1926. In the study of grafic artifacts memory it is important to take into account and to know well the technology available at the time in which they were produced. Technology can impose limits on the development of graphic work, but can, as well, expand its possibilities. In this sense, this article intends to investigate the technology used in the printing of Revista de Pernambuco's covers (1924-1926) relating it to the existing graphic practices at that time. Thus, it describes not only the scenario of the graphic industry of Pernambuco, but also the printing technologies used in the early twentieth century. By knowing the production of these artifacts, this article seeks to contribute to a better understanding of the graphic practice in the state of Pernambuco at that period.
\end{abstract}

Keywords: graphic memory; print technology; autotype. 


\section{Introdução}

Com a evolução dos meios de impressão e o aumento do público leitor, artefatos impressos se tornam uma das mercadorias que mais se expandiram no século XIX. As inovações tecnológicas possibilitaram a criação de novos veículos de comunicação, como a revista ilustrada (CARDOSO, 2008).

Inicialmente as revistas não possuíam capas atraentes, com imagens em cores, como as de hoje em dia. O visual das revistas dependia quase sempre da tipografia e as ilustrações eram usadas apenas para decoração de letras, títulos e molduras impressas a partir de gravuras em madeira, até a inserção da litografia aprimorando a qualidade das imagens (ALI, 2009). No Brasil as primeiras revistas ilustradas surgem no século XIX e a grande maioria usava a litografia como técnica de impressão. Na virada do século o uso de autotipia - comumente chamado de clicheria - era frequente na reprodução destas imagens.

No estudo da memória gráfica ${ }^{1}$ é importante levar em conta e conhecer bem a tecnologia disponível à época em que estes artefatos foram produzidos. A tecnologia pode impor limites ao desenvolvimento de um trabalho gráfico, mas pode também ampliar as possibilidades. Cardoso (2008) aponta a importância de diferentes informações para a compreensão de artefatos de design.

"O cruzamento de dados de ordem econômica e cultural com outras informações de natureza tecnológica e artística faz-se essencial para dar sentido à diversidade de manifestações do design em diferentes contextos (CARDOS, 2008, p.56)."

Neste sentido, este artigo procura fazer uma abordagem dos processos de impressão utilizados nas capas da Revista de Pernambuco (1924-1926) dentro da prática gráfica vigente na época em foram desenvolvidas. Para isso descreve o cenário da indústria gráfica pernambucana e as tecnologias de impressão usadas no início de século XX. Desta forma, busca contribuir para o conhecimento da produção deste artefato e, consequentemente, colaborar para o entendimento da prática gráfica no estado de Pernambuco.

A própria revista nos contou muito sobre a técnica utilizada em sua produção. Informações sobre onde eram impressos estes artefatos, as máquinas que utilizavam entre outras coisas, podem ser percebidas não só através de uma análise visual meticulosa como também pelas informações imagéticas espalhadas nas páginas das revistas durante os anos de sua veiculação. Além disso, através das publicidades, podemos observar as máquinas e os recursos técnicos de impressão comercializados à época.

Entre 1910 a 1930 aconteceu uma efervescência na área editorial no país com diversas produções de revistas ilustradas (CARDOSO, 2008). Na capital pernambucana a situação não era diferente do que ocorria em algumas outras capitais, mas especialmente Rio de Janeiro e em São Paulo. Nesta época Recife era a terceira maior cidade do país, cujo poder econômico tinha se mantido com criação de usinas e aumento na produção e exportação de açúcar, que apesar disso, vinha perdendo sua proeminência econômica e política no contexto nacional. O estado de Pernambuco e sua capital precisavam acompanhar as inovações tecnológicas recentes. Da mesma forma que surgiam diversos periódicos no sudeste do país, em Pernambuco também começam a editar algumas publicações. Aliás, desde o século XIX eram produzidos periódicos no estado de Pernambuco. Entre 1900 e a década de 1930, algumas revistas merecem destaque como as apontadas por Cavalcante (2012) como, Cri-Cri (1908), A Pilheria (1921), Revista do Norte (1923),

\footnotetext{
${ }^{1}$ Segundo Farias (2014, p. 1), memória gráfica pode ser entendida como "uma linha de estudos que pretende revisar o significado e o valor dos artefatos visuais, e em particular dos impressos efêmeros, para estabelecer um sentido de identidade local através do design" (tradução dos autores).
} 
Revista da Cidade (1926), Pra Você (1932). Para este estudo destacamos em especial a Revista de Pernambuco (1924) que com suas capas atraem o olhar do leitor pela criatividade, versatilidade e pelo domínio da técnica gráfica usada pelo autor.

\section{As capas da Revista de Pernambuco}

A Revista de Pernambuco foi produzida e editada pelo órgão do estado de Pernambuco entre os anos 1924 a 1926, no governo de Sérgio Loreto. Sua primeira edição surgiu em 2 de julho de 1924 e a última em 28 de outubro de 1926. Teve como principal capista Heinrich Moser Moser, alemão radicado em Pernambuco desde 1910. Com tiragem mensal, algumas edições chegaram a ter 80 (oitenta) páginas (NASCIMENTO, 1975).

Em geral, sua imagética, fotos, ilustrações, em especial as capas produzidas por Moser, divulgavam o progresso tecnológico, projetos urbanos e estilos modernos de vestir seguindo a moda europeia. Os artigos desta revista, tanto os que tratavam das obras do governo como as matérias jornalísticas e culturais, transmitiam um projeto de modernidade.

Figura 1 - Capas da Revista de Pernambuco.
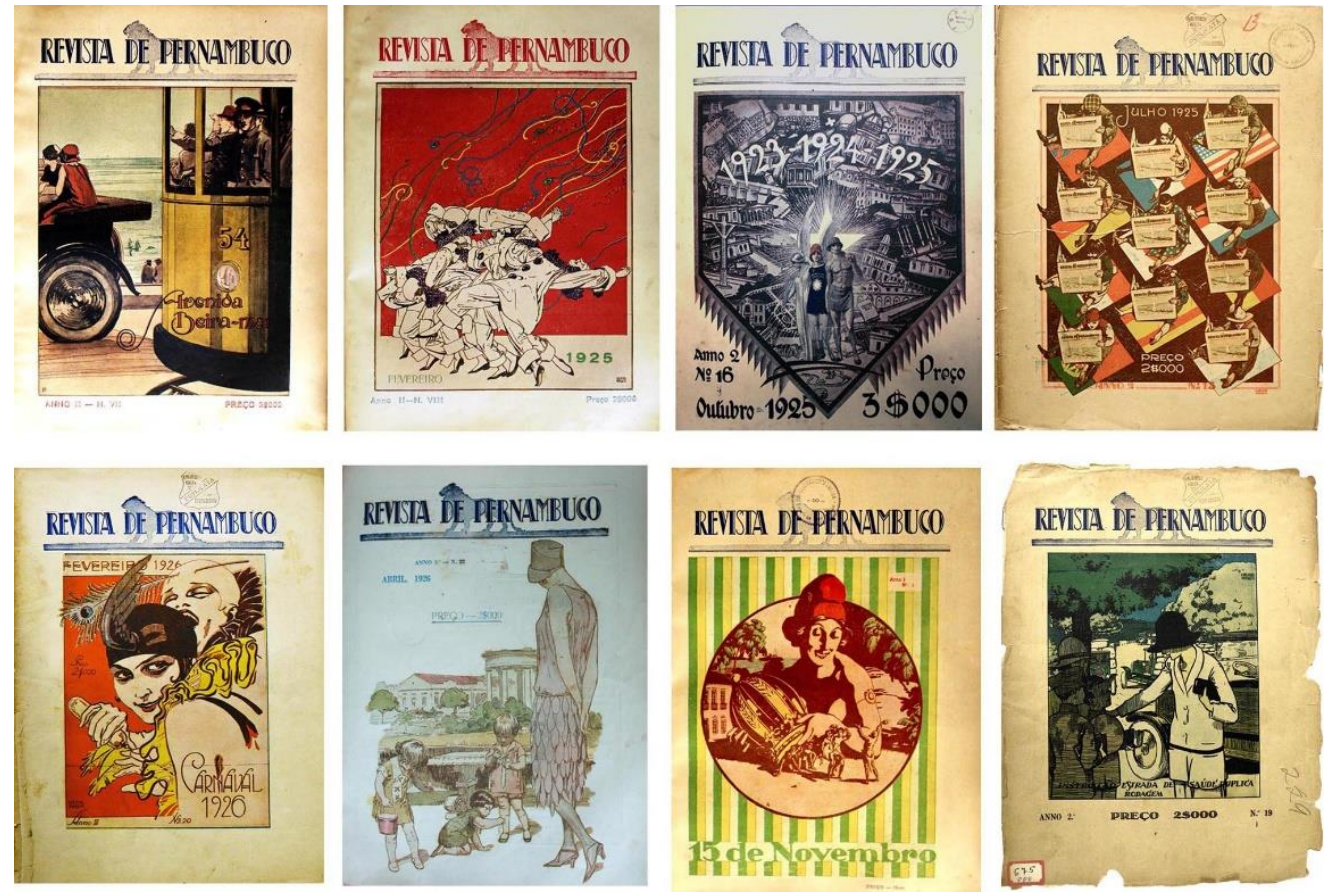

Fonte: Biblioteca Pública do Estado de Pernambuco (BPE/PE).

Observamos um crescente interesse na Revista de Pernambuco por pesquisadores na área da história do design pernambucano ou mesmo por estudantes de graduação do curso de Design. Porém, as maiores informações encontradas sobre esta revista nos foi dada pelo historiador renomeado, Luiz do Nascimento. Ele descreve alguns aspectos técnicos e aponta colaboradores que participaram da construção deste impresso, elencando uma quantidade bastante significativa de intelectuais da época no corpo editorial. Destaca que todas as capas foram ilustradas pelo artista Heinrich Moser, sendo apenas uma elaborada pela empresa de Artes Decorativas. No entanto, percebemos que, já no último ano, duas capas utilizaram fotografia, sendo uma delas identificada com a assinatura de T. Filhos, que supomos ser do fotogravador Telles Junior. De maneira que, 
dentre o total de 28 capas até agora catalogadas, 25 (vinte e cinco) foram ilustradas por Heinrich Moser, 1 (uma) pela empresa de Artes Decorativas e 2 (duas) com a utilização de fotografias.

\section{Processos investigativos}

Este artigo é parte da pesquisa sobre as capas da Revista de Pernambuco produzidas pelo artista alemão Heinrich Moser. Tem como foco abordar os mecanismos técnicos utilizados na produção destas revistas, e em especial, suas capas. Para isto, empregamos tanto métodos investigativos de natureza analítica visual, quanto histórico.

Como suporte teórico para conhecimento da história da indústria gráfica, levantamos bibliografia sobre a evolução das técnicas de impressão e como estas refletiu no estado de Pernambuco no início do século XX. Neste sentido, fundamentamos através de autores como Meggs (2009), Fonseca (2016), Cardoso, (2008), Nascimento (1975), Cavalcante (2012), Barreto Campello (2014) entre outros. Para análise visual das capas usamos o autor Bamber Gascoigne (2004).

Inicialmente fizemos registros fotográficos das capas da revista em análise, porém sentimos a necessidade de um exame mais detalhado das imagens. Para isso utilizamos um microscópio digital USB Novacom, com zoom de até 1.000 vezes. Desta forma, com as imagens ampliadas, pudemos observar detalhadamente as peculiaridades das impressões e quantidade de cores usadas. Também fizemos uma breve investigação no miolo da revista, onde encontramos informações e imagens sobre a tecnologia utilizada em sua impressão.

Os acervos públicos visitados foram a coleção de obras raras da Biblioteca Central Blanche Knopf, pertencente à Fundação Joaquim Nabuco e a Biblioteca Pública do Estado de Pernambuco (BPE), no setor das Coleções de Obras Raras. Desta forma, foram catalogadas 28 capas dentre elas, 25 produzidas pelo artista Heinrich Moser.

Como parte de uma dissertação de mestrado (MARIZ, 2018) que tem foco no trabalho de Moser, especialmente na análise gráfica dessas capas, este artigo busca lançar um olhar sobre as técnicas de impressão destas produções. Para isto, a seguir faremos um sobrevoo na tecnologia existente na época de sua produção.

\section{Tecnologias de impressão}

Na segunda metade do século XIX ocorreram evoluções importante que possibilitaram a reprodução de imagens. Desde o uso secular da xilografia, veio a litografia ${ }^{2}$ e a gravura em metal que foram aperfeiçoadas para uso comercial e industrial. Desta forma tornou-se possível imprimir em larga escala e a preços baixos. Estes avanços tecnológicos culminaram na fotogravura na década de 1880 (CARDOSO, 2008).

Na fotogravura as placas eram gravadas em relevo, através de corrosão do metal e depois montadas sobre uma peça de madeira ou metal para deixá-la na altura adequada para impressão na matriz tipográfica (CRAIG, 1980). Este artefato, denominado clichể $\hat{\text { t }}^{3}$ trazia a possibilidade de se imprimir imagem e texto juntos. Desta forma, este sistema apresentava vantagem em relação à litografia pelo fato de que o material poderia ser impresso de uma vez, isto é, o clichê junto com os

\footnotetext{
2 Litografia é uma impressão planográfica baseada na repulsão entre óleo e água no qual certas partes da superfície podem ser receptivas à tinta enquanto outras rejeitá-la (GASCOIGNE, 2004)

${ }^{3}$ Placa de metal, com imagens ou dizeres em relevo, obtida por meio da estereotipia, galvanotipia ou fotogravura, e destinada à impressão em máquina tipográfica (Porta, 1958).
} 
tipos móveis, diferentemente da litografia que necessitava tiragens separadas. Porém, Fonseca (2016) aponta que este tipo de produção, da matriz em relevo a partir da corrosão do metal, não permitia detalhamentos mais finos característicos da litografia (FONSECA, 2016).

Embora a litografia proporcionasse uma qualidade visual através de detalhes delicados e variações tonais, não tinha a capacidade de reprodução de imagens fotográficas. Desta forma, diversos experimentos foram desenvolvidos com o objetivo de aplicar a fotografia em impressos. De maneira que, com o intuito de reproduzir as nuanças tonais encontradas em uma fotografia, foi utilizado filtros que separava tons contínuos em pontos de tamanho variado. Assim foram as pesquisas do inglês Henry Fox Talbot, Georg Meisenbach, em 1882 e Frederick E. Ives (1856-1937) (MEGGS, 2009, p. 192).

Figura 2 - Ampliação de retícula com variação de tamanho dos pontos. Meio-tom com 34 linhas.

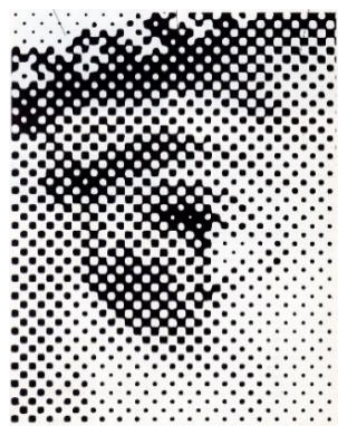

Fonte: CRAIG (1980).

Assim este processo de fotogravação, conhecido como autotipia ou clichê a meio-tom, viabilizaram as reproduções de imagem com variação de tonalidade nas impressões e desta forma a fotografia pode enfim ser reproduzida em impressos. No Brasil, na última década do século XIX, tem-se registro de algumas experimentações feitas na imprensa carioca na tentativa de reproduzir fotografias. Fonseca (2016) aponta que a primeira fotografia em periódicos no Brasil teria aparecido em um suplemento da revista d'A Cigarra, no ano de 1895.

As retículas nos clichês eram medidas por números de linhas. Quanto maior número de linhas por centímetro, melhor a qualidade. Além disso, para melhor resultado era necessário conhecer a retícula adequada para cada tipo de papel. No entanto, para reprodução de uma imagem com tonalidades uniformes, sem tons intermediários, não era necessário o uso de retícula. Este tipo de clichê era denominado "clichê a traço" (CANTERO, 1971).

Inicialmente, o processo fotomecânico usava apenas uma cor e depois vários experimentos foram desenvolvidos para introdução das cores na impressão. A princípio utilizavam três cores (tricromia): azul esverdeado, carmim e amarelo, sem a necessidade do uso do preto. As linhas de retícula de cada cor se posicionavam em diferentes angulações. Somente em 1934 é que o processo fotomecânico de imagens coloridas se aperfeiçoou com a introdução do preto e a padronização das outras cores (BARROS, 2008).

\subsection{Tecnologia da indústria gráfica pernambucana no início do século $X X$}

Segundo Agra Jr. (2011), existem poucas informações sobre parte da História Gráfica recifense. Aponta que, registros sobre as artes gráficas pernambucanas no século $X X$ além de escassas 
apresentam abordagem distintas daquelas encontradas no universo do design, com algumas exceções como o trabalho O Gráfico Amador de Cunha Lima (1997) e outros mais voltado a litografia.

A atividade gráfica em Recife através do uso de prensa tipográfica remete a 1817, quando os revoltosos da Revolução Pernambucana se apoderam de uma impressora e imprimem o manifesto O Preciso (BARRETO CAMPELLO, 2011) (CUNHA LIMA, 1997). A partir daí, foram desenvolvidas diversas produções gráficas no século XIX.

As imagens que estampavam estes impressos, incialmente eram importadas da Europa. Isto acontecia porque na cidade ainda não se tinha mão de obra especializada para produção da técnica. O Maribondo, publicado em 1822 em Recife, foi um dos primeiros periódicos pernambucano a estampar imagens (FERREIRA,1976).

Figura 3 - Ilustração em O Maribondo, 1922.

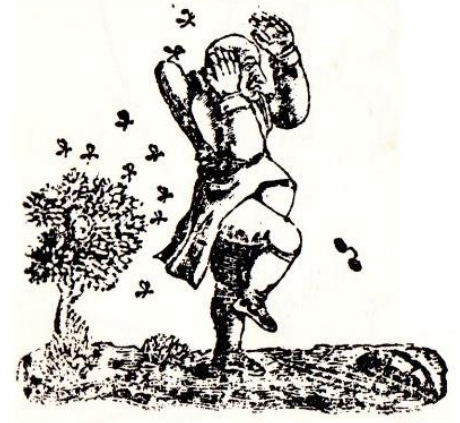

Fonte: Ferreira (1976, p. 82).

Mais adiante os impressos ilustrados se expandem no país e, consequentemente, em Pernambuco. O uso da autotipia - comumente chamada de clicheria - possibilitaram impressão em bi e tricromia em impressos. Embora as pesquisas sobre a chegada desta técnica no estado estejam ainda incipientes, uma melhoria neste tipo de impressão pode ser percebida a partir da década de 1920. Assim, as capas da Revista de Pernambuco demostram o apurado domínio desta técnica de impressão (CAVALCANTE, BARRETO CAMPELO, 2014).

Há relatos que observam o uso de clichês em revista já no início do século XX. Em seu livro História da Imprensa de Pernambuco (1821-1954), Luiz do Nascimento (1975) se refere ao uso do clichê no ano de 1901 em diversos periódicos. A partir de um levantamento feito em 64 periódicos pernambucanos entre os anos de 1887 a 1958, Cavalcante (2012) aponta outros que utilizavam a matriz em clichê para impressão no início da década de XX:

\footnotetext{
“Das duas primeiras décadas do século XX em Pernambuco, encontramos 10 publicações, como o periódico Cri-Cri, de 1908, e a Revista Moderna, de 1906, ambas já possuíam evidências da utilização da matriz em clichê para reprodução de fotogravuras e caricaturas, letreiramentos e capas" (CAVALCANTE, 2012, p. 27).
}

Também existem poucas informações sobre as empresas que confeccionavam os clichês - as chamadas clicherias - na cidade do Recife no início do século XX, no entanto identificamos algumas anunciantes deste tipo de serviço na cidade, no Catálogo de Propagandas em Revistas Recifenses das Décadas de 1910 a 1950 (MACÊDO, 2009). Dentre estes, destacamos a propaganda Photo- 
Gravador Benevenuto Telles Filho, em edições na Revista de Pernambuco entre 1925 e 1926, na revista Pra Você $(1932,1933)$ e na e revista Contraponto $(1946,1947)$. Outra empresa que possuía a direção de Benevenuto ${ }^{4}$, o Atelier de Gravuras Diário da Manhã, anunciou na revista para Pra Você. Agra Júnior (2011), Cavalcante e Barreto Campello (2014) observam também assinatura desta clicheria em outras revistas pernambucanas. Já a Drechsler \& Cia, anunciou frequentemente na Revista de Pernambuco e com bastante destaque, no formato de $1 / 4$ de página, diferentemente do pequeno anúncio de Benevenuto. Devido à grande quantidade de anúncios nesta revista e por ser uma anunciante quase que exclusiva do ramo gráfico, arriscamos sugerir que a Drechsler fornecia algum tipo de serviço para a Revista de Pernambuco, até mesmo clichês.

Figura 4 - Anúncios da Drechsler \&Cia e da Photo-gravura Benevenuto Telles Júnior na Revista de Pernambuco.

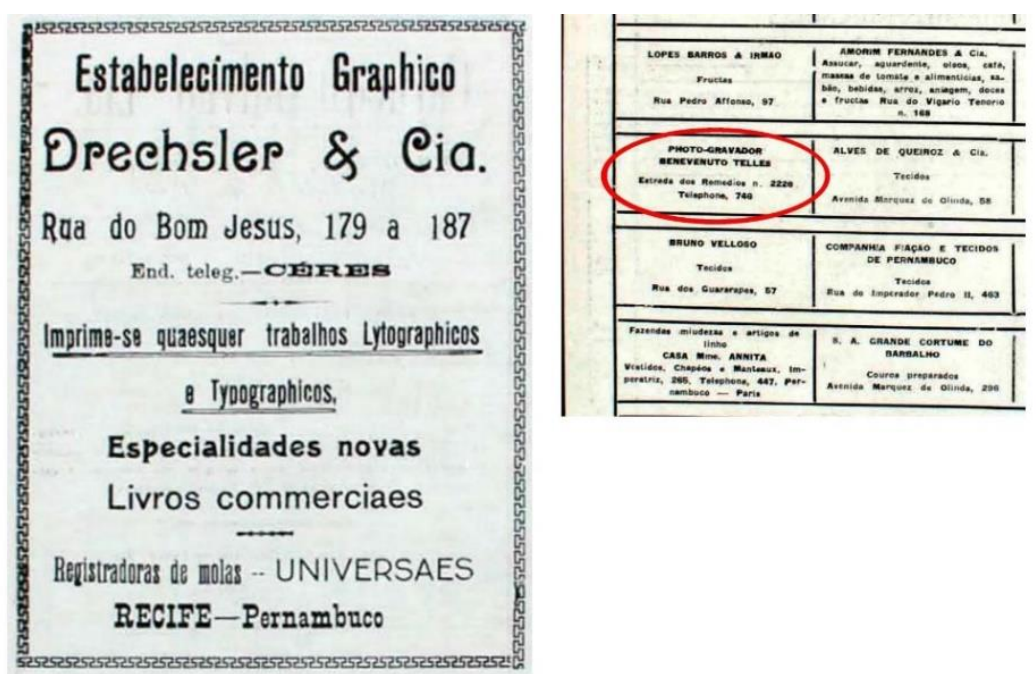

Fonte: Biblioteca Pública do Estado de Pernambuco (BPE/PE).

Barreto Campello (2011) aponta que nesta transição da litografia para o uso de clichê, provavelmente os profissionais que trabalhavam com a antiga técnica migraram para este novo processo, devido a experiência que possuíam com o uso das cores para uma boa reprodução da imagem. Assim, a técnica da litografia em revistas ilustradas é substituída pela autotipia através do uso de clichê reticulado e suas possibilidades de reprodução de fotografias. A litografia ainda será usada para rótulos por mais algum tempo.

\section{Discussão dos Resultados - Tecnologia gráfica utilizada na Revista de Pernambuco}

Para investigar a técnica de impressão utilizada nas capas da Revista de Pernambuco, nos baseamos pelo livro How to Identify Prints, de Bamber Gascoigne (2004). Como sugerido pelo autor, trabalhamos com as imagens ampliadas que nos proporcionaram distinguir o tipo de impressão. Para isto utilizamos um microscópio digital, com capacidade de ampliação de até 1.000 vezes.

Várias características nos levaram a concluir, que as imagens produzidas por Moser para estas capas, foram em relevo, com clichê. As primeiras características observadas foi o uso de retícula mecânica e a percepção de um certo relevo na parte de trás do papel. Relevos deste tipo

\footnotetext{
${ }^{4}$ Filho do artista Jerônimo José Telles Júnior (1851-1914) conhecido como Telles Júnior.
} 
comumente se apresentam devido à forte pressão na prensa tipográfica, mas como aponta Gascoigne (2004) não se pode apenas concluir por esta característica, pois em papéis grossos podem não ser percebidos.

Figura 5 - Capa da Revista de Pernambuco no 18. À direita, um corte ampliado apresentando uso de retícula mecânica.

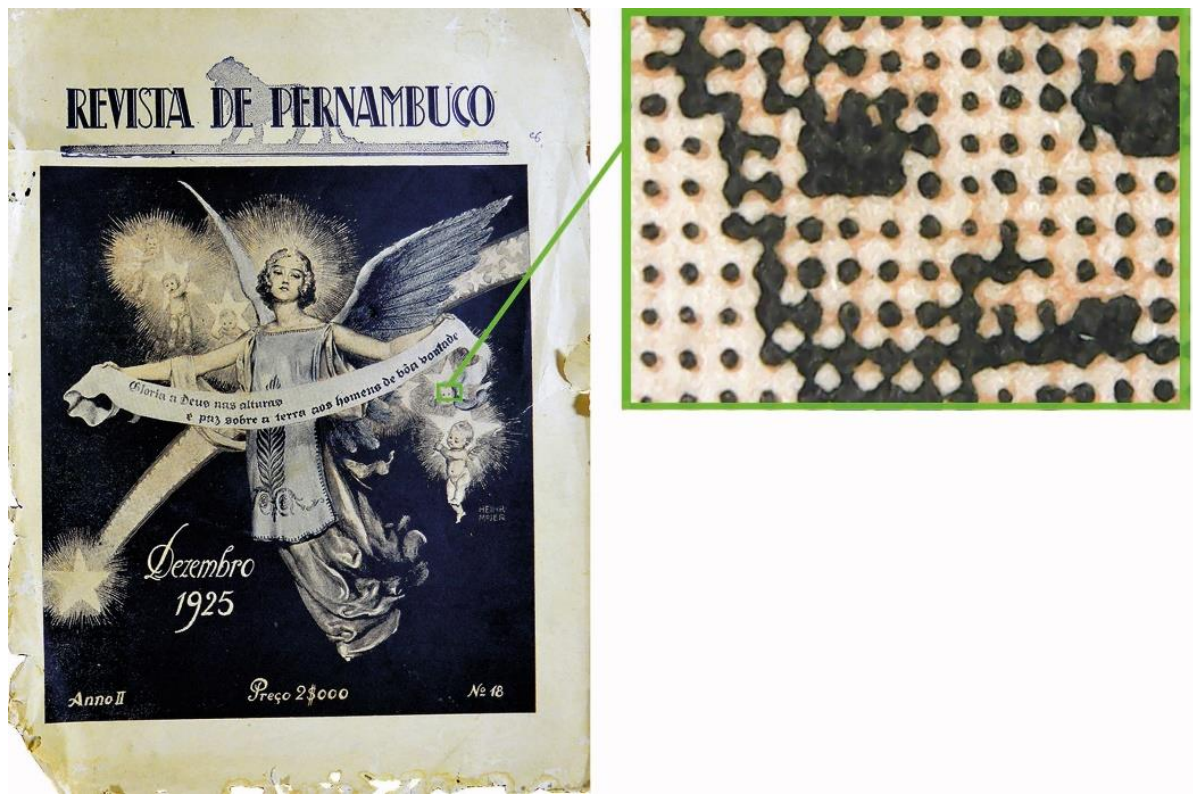

Fonte: Biblioteca Pública do Estado de Pernambuco (BPE/PE).

Outras características de impressão por relevo apontada por Gascoigne (2004) foram quanto ao acúmulo de tinta nas bordas da imagem, enquanto que em litografia ou offset as bordas são mais planas. Este acúmulo de tinta é ocasionado pela pressão da imagem em relevo sob o papel na prensa tipográfica. Esta característica é mais perceptível na impressão em papéis lisos, como o couchê.

Figura 6 - Impressão com acúmulo de tinta nas bordas da imagem. Revista de Pernambuco, no 25.

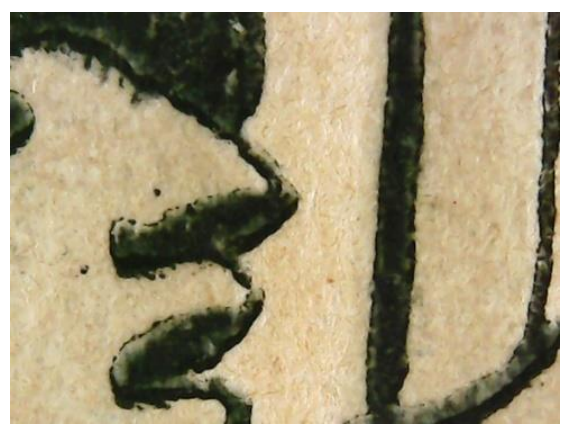

Fonte: Biblioteca Pública do Estado de Pernambuco (BPE/PE).

Observar imagens em meio tom, com uso de retículas, foi outra sugestão apontada pelo autor para distinguir impressões antigas. Em gravura, por exemplo, os pontos são quadrados e tamanhos iguais. Na impressão em relevo ou offset os pontos das retículas apresentam tamanhos diferentes e redondos, chegando nas áreas mais escuras apresentar efeito reverso, isto é, formar 
pontos brancos. Na impressão em relevo os pontos possuem limites mais nítidos, limpos e nas áreas mais escuras estes pontos se fundem, como mostra figura abaixo. Já no offset os pontos têm limites mais suaves.

Figura 7 - Ampliações mostram retículas com diferentes tamanhos de pontos, chegando na área escura apresentar efeito reverso com formação de pontos brancos. Foto da Avenida Boa Viagem, 1925.
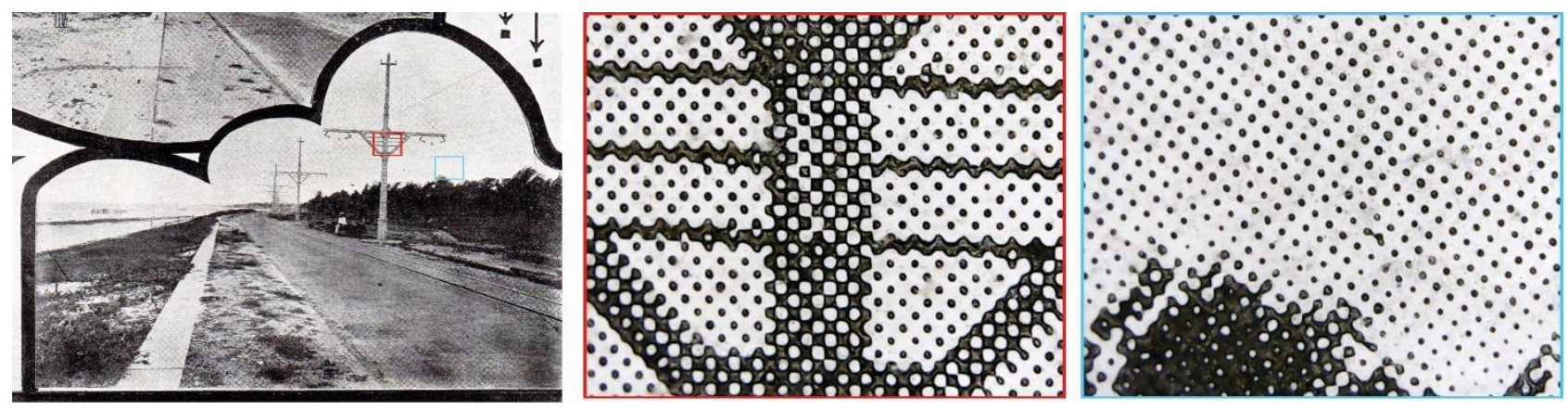

Fonte: Acervo particular da autora. Revista de Pernambuco, no 18.

Nesta investigação percebemos que as capas das primeiras edições da Revista de Pernambuco apresentam impressão com cores chapadas, sem uso de retículas. A partir da edição número 3 existe a introdução da retícula. Também percebemos que algumas capas utilizam uma mescla do uso do clichê a traço com o clichê reticulado. Talvez por opção projetual, ainda houve uso exclusivo do clichê a traço na edição $n=25$.

Figura 8 - À esquerda uso de clichê a traço, à direita clichê reticulado e no meio uso dos dois tipos.
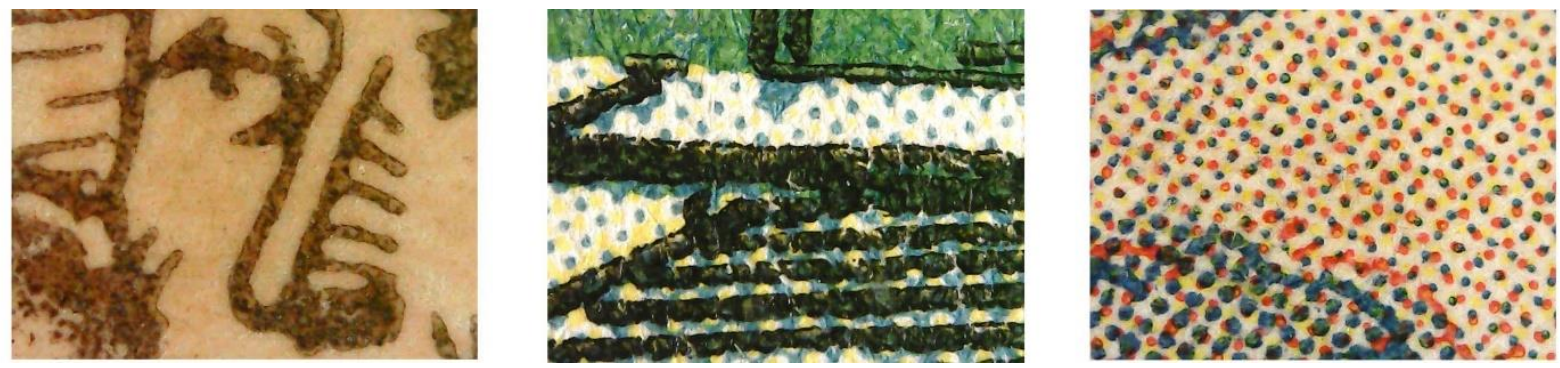

Fonte: Revista de Pernambuco n¹, n¹9, n9. Biblioteca Pública do Estado de Pernambuco (BPE/PE).

No uso dos clichês reticulados com variações de cores, percebemos que a maior parte das capas fizeram uso de bicromia (duas cores) e em seguida uso de tricromia (três cores). As cores como vermelho, azul e amarelo foram muito usadas. Interessante observar que as duas capas que exibem fotos, já nas edições finais, no 24 e no 27, fazem uma criativa tentativa de inserção das cores. Em uma destas capas, se não houvesse assinatura indicando que a imagem é uma foto, sua coloração proporciona ideia de uma ilustração. Já a capa da direita, a solução para a inserção da cor foi dada através de uma de um chapado amarelo no fundo. Estes exemplos mostram como foi superada a limitação técnica que existia na reprodução de fotos coloridas. 
Figura 9 - Inserção de fotos nas capas com uso de cores.
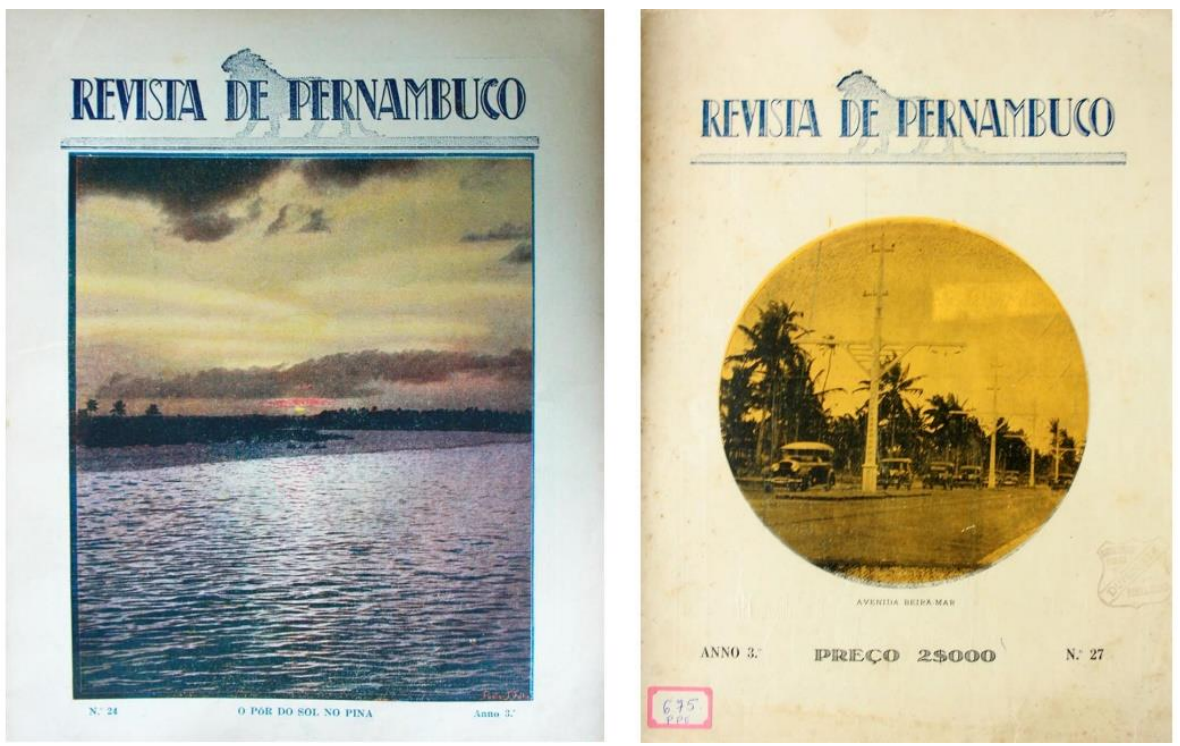

Fonte: Revista de Pernambuco no 24 e no27. Biblioteca Central Blanche Knopf - Fundaj.

A utilização da autotipia nestas revistas também pode ser atestada em diversas legendas que claramente explicitam o uso do clichê na reprodução das fotos. Encontramos este tipo de legenda nas últimas edições do ano de 1926, como por exemplo, a revista de no 27 (setembro de 1926), uma das últimas. Nela, em um conjunto de fotos que homenageia o médico sanitarista Dr. Amaury de Medeiro, sua legenda aponta explicitamente o uso de clichê através da seguinte informação: "Os nossos clichês attestam a elegância dessa distincta reunião do "set" social recifense."

Figura 10 - A legenda deste conjunto de fotos revela o uso do clichê para reprodução da imagem.

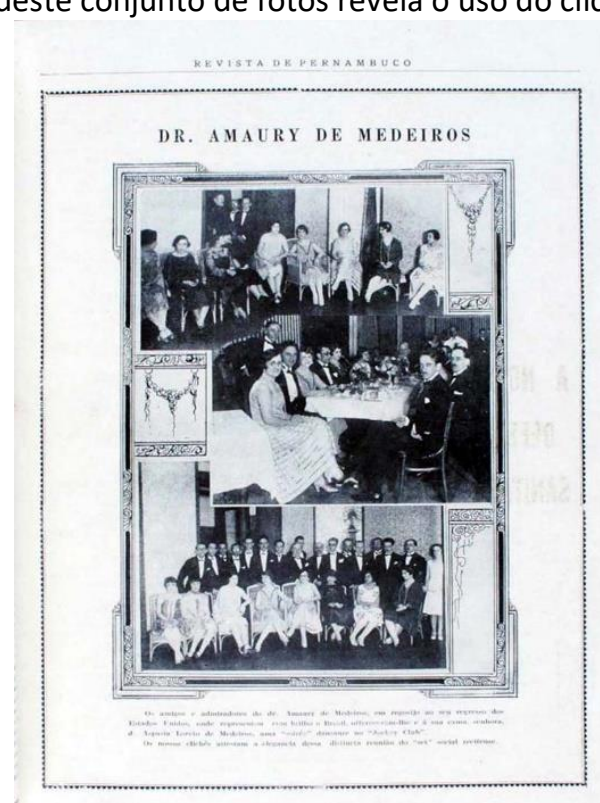

Fonte: Biblioteca Pública do Estado de Pernambuco (BPE/PE). 
Outras informações técnicas acerca da Revista de Pernambuco podem ser identificadas no seu expediente: "elaborada pelo corpo Redacional do Diário do Estado" e "editada pela Repartição de Publicações Oficiais do Estado de Pernambuco". Esta repartição foi criada no ano de 1924 juntamente com o Diário do Estado e lá se editava tanto este diário, como a Revista de Pernambuco. Em 1926, último ano do governo de Sérgio Loreto, a Repartição de Publicações Oficiais do Estado de Pernambuco foi substituída pelo Departamento de Imprensa Oficial e depois para Companhia Editora de Pernambuco - Cepe, indústria gráfica de referência em Pernambuco atualmente. Em 1944 o Diário do Estado passou a se chamar Diário Oficial (CEPE, 2018).

As fotos espalhadas em suas edições nos contam, de forma imagética, sobre suas oficinas e processos. É o caso das imagens apresentadas nas edições $n=5, n=17$ e $n$ 우 19, que mostram fotos da Repartição de Publicações Oficiais do Estado de Pernambuco, seu maquinário e os processos impressão. Não encontramos texto referente a estas fotos, apenas legendas que revelam algumas informações. 0 título das duas páginas da edição no 5, apontam o local da impressão: "Repartições de Publicações Officiaes - Seccão Technica". Na página da esquerda, na foto de cima, vemos um grupo de detentos como operários da subseção de encadernação e tipografia. Pelo gradil encontrado na parte de trás da foto, arriscamos sugerir que o local poderia ser a antiga casa de detenção no Recife, transformada muito anos depois e existente até hoje, na Casa da Cultura. Ainda nesta página, na foto abaixo, mostra os operários na oficina de tipografia, onde podemos identificar as matrizes de impressão tipográfica à direita e à esquerda as máquinas de Linotipo. Na página da direita, a foto de cima mostra em destaque operários na máquina de Linotipo e abaixo a impressora que imprimia o Diário do Estado, chamada Machina Duplex Printing Press. Como podemos perceber nesta foto, o papel era matéria prima necessária nesta época de tantas transformações gráficas. Neste sentido, a edição no 25 (Revista de Pernambuco, 1925) relata a implantação de uma fábrica de papel de grande porte no estado, mostrando mais uma vez o crescimento da área gráfica no estado (Revista de Pernambuco, 1925).

Figura 11 - À esquerda, detentos trabalhando na Repartição de Publicações Oficiais do Estado de Pernambuco e à direita maquinário utilizado para edição e impressão dos impressos. Revista no 5, 1924.
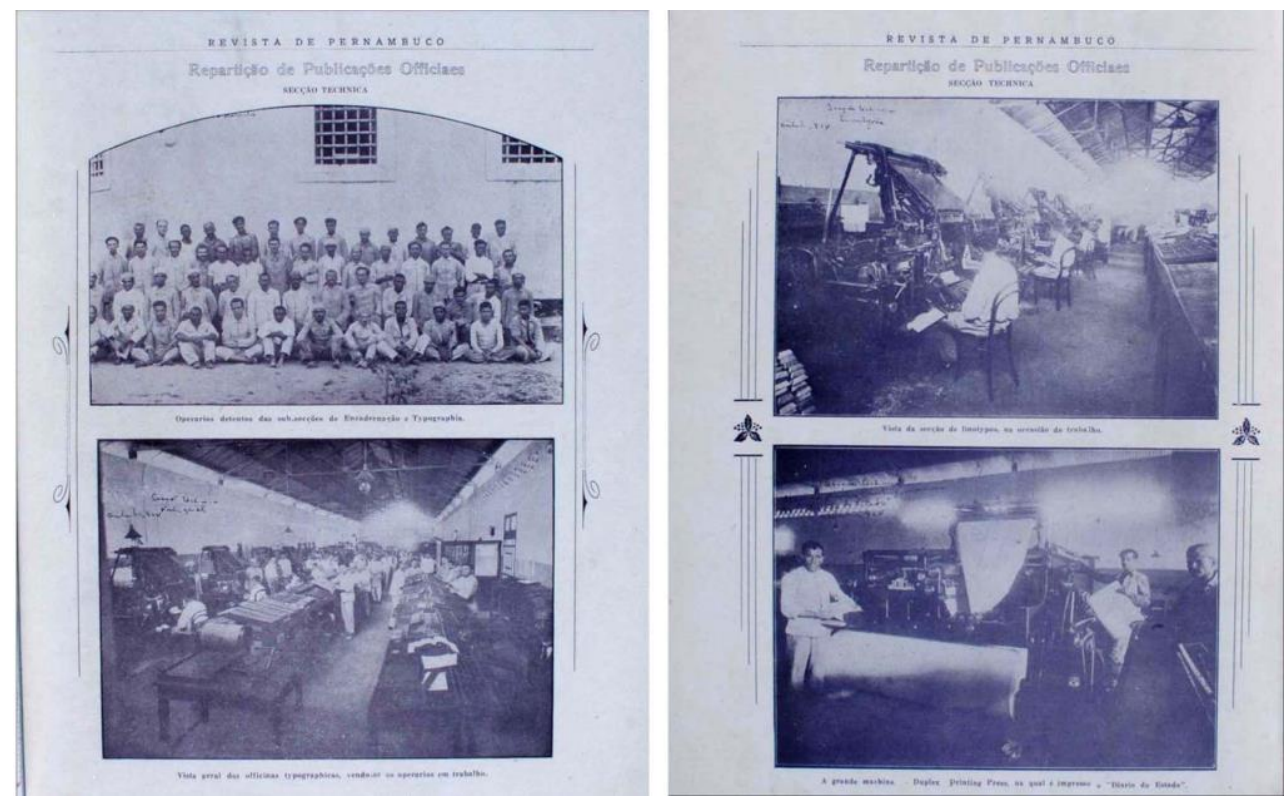

Fonte: Biblioteca Pública do Estado de Pernambuco (BPE/PE). 
A edição no 17 (figura 34), também dedica uma página para a Repartição de Publicações Oficiais do Estado de Pernambuco com as seguintes legendas: "1 - Seç̧ão de composição; 2 - Seç̧ão de linotipia; 3 - Minervas de impressão; 4 - Vista parcial da machina Babcock, onde é impressa a Revista de Pernambuco."

Figura 12 - Oficina onde se imprimia a Revista de Pernambuco. Revista no 17, 1925.

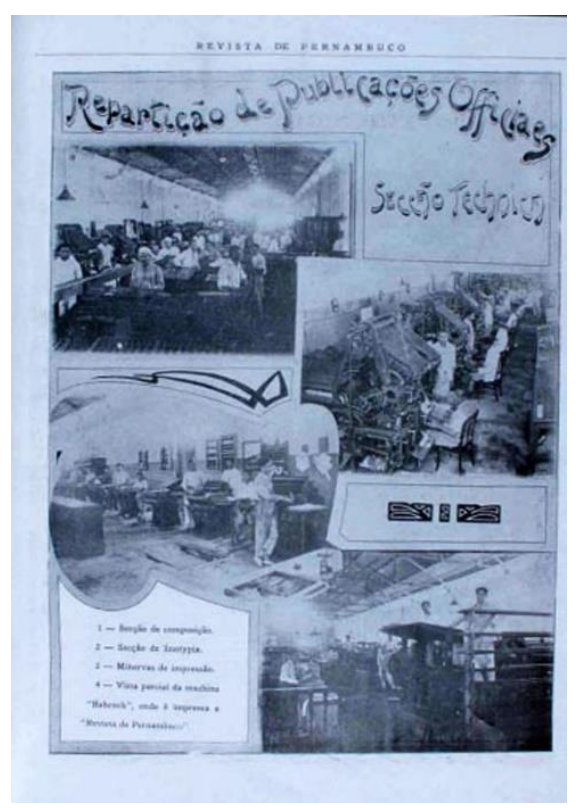

Fonte: Biblioteca Central Blanche Knopf - Fundaj.

A primeira foto mostra os operários e logo à frente diversas caixas de tipos. À direita as máquinas de linotipo. Na segunda foto é dado destaque para as máquinas de linotipo; já na terceira foto são apresentadas várias máquinas Minerva ${ }^{5}$. Este tipo de impressora foi usado comercialmente até a década de 1980. A quarta foto nos revela a máquina que imprima a Revista de Pernambuco, porém não encontramos referências sobre esta impressora da empresa inglesa Babcock.

Na revista $\mathrm{n}$ - 19, mais uma vez, retratam o local de onde se editavam tanto o Diário do Estado quanto a Revista de Pernambuco. Destaque para a máquina de impressão, Machina Duplex.

\footnotetext{
${ }^{5}$ Máquina na qual duas superfícies planas se juntam para fazer uma impressão, diferentemente de máquina cilíndricas ou rotativas (CRAIG, 1980).
} 
Figura 13 - Oficinas da Repartição de Publicações Oficiais. Revista no 19, 1925.

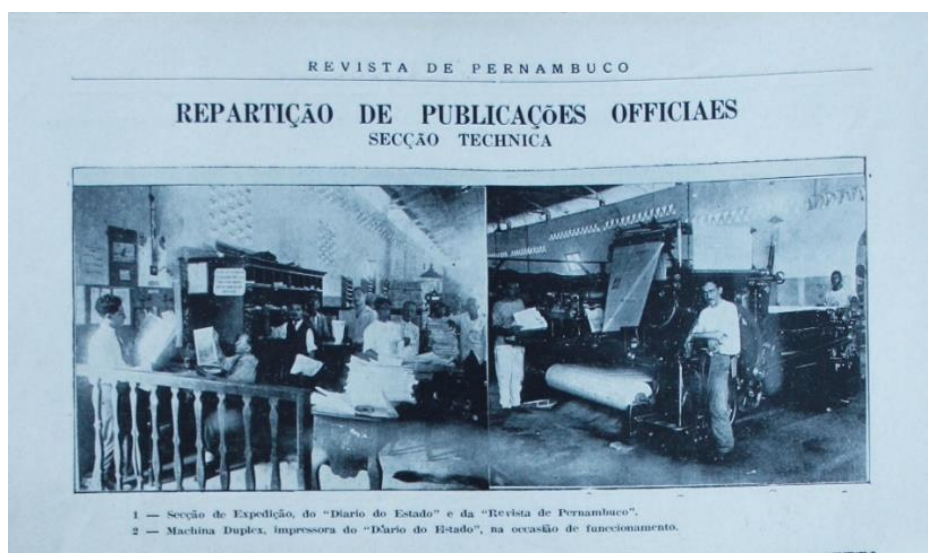

Fonte: Biblioteca Pública do Estado de Pernambuco (BPE/PE).

Mais adiante entra a era do offset. Chega ao Brasil em 1922, inicialmente utilizado em empresas comerciais, em especial a empresa Souza Cruz. Já a primeira revista a utilizar o offset foi a Cinearte em 1926 (CARDOSO, 2008). Em Pernambuco, a chegada do offset aconteceu através da Dreschler \& Cia, em 1926, (LIMA, 1998). Interessante observar que apesar da chegada do offset em Pernambuco ser citada no ano de 1926, já no ano de 1925, na edição no 17 da Revista de Pernambuco, como também em outras edições, encontramos uma propaganda da empresa $C$. Fuerst \& Cia Ltda anunciando uma máquina offset da fábrica Planeta, a mesma fábrica da qual a Dreschler adquiriu sua impressora. A C. Fuerst \& Cia Ltda possuía escritório em São Paulo, Rio de Janeiro e filial em Recife. Esta também oferecia serviço de instalações de tipografias e litografias além de diversos artigos gráficos. Assim percebemos que a técnica offset era a grande novidade tecnológica e já teria então possíveis compradores em Pernambuco mesmo anteriormente ao que alguns autores alegam ter sido a chegada do offset na região.

Figura 14 - Anúncio de máquina offset na Revista de Pernambuco antes de 1926.

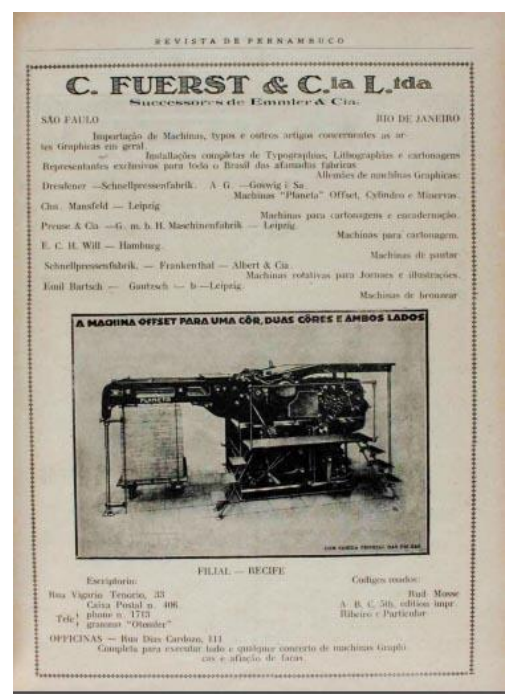

Fonte: Biblioteca Pública do Estado de Pernambuco (BPE/PE). 


\section{Conclusão}

Para analisar as capas da Revista de Pernambuco do ponto de vista do design é realmente relevante observar as transformações ocorridas na indústria gráfica local. Como sinaliza Sobral (2005), as decisões projetuais são frequentemente norteadas pelos aspectos tecnológicos. Desta forma, mudanças nos processos gráficos influenciam diretamente na concepção e estética utiliza da nas imagens de um impresso.

Desta forma, observamos neste estudo, que o desenvolvimento da indústria gráfica pernambucana no início do século XX buscou acompanhar as novidades tecnológicas que ocorriam em capitais no sul e sudeste do país.

A metodologia utilizada para investigação da técnica utilizada nesta revista se revelou satisfatória. Desta forma, a análise visual, com uso de microscópio digital e uma revisão bibliográfica da técnica de impressão utilizada na época, além de informações encontradas no próprio artefato, foi relevante para nos apontar os caminhos sobre sua feitura. Assim percebemos o uso frequente do clichê nesta revista não só nas capas, mas também no miolo com grande quantidade de fotos espalhadas em várias páginas.

A análise das capas da Revista de Pernambuco entre 1924 a 1926, mostra como novas tecnologias afetaram o design da época. A variação de recursos gráficos, como a fotogravação possibilitou o uso de clichê reticulado, permitindo maior gama de tons e distintos estilos visuais. As combinações de cores e efeitos produzidos nestas capas mostram um amadurecimento desta técnica conhecida como autotipia. Destaque especial para as capas produzidas pelo ilustradordesigner Heinrich Moser, que revela o seu conhecimento no uso das cores e dos recursos gráficos existentes na época. Tudo isto aliado à sua habilidade profissional possibilitou surpreendes resultados.

No geral, é possível perceber, através da Revista de Pernambuco, que a agilidade proposta pela inovação do processo fotomecânico garantiu capas de qualidade excepcionais, além de edições com tiragens mensais constante e com uma quantidade relevante de páginas ilustradas. Desta forma mostra o aprimoramento do parque gráfico pernambucano.

Enfim, este artigo busca cooperar para o estudo da memória gráfica brasileira e revela a necessidade de estudos mais aprofundados sobre a tecnologia da autotipia no estado de Pernambuco.

\section{Referências}

AGRA Jr., Jarbas Espíndola. 2011- Memória Gráfica Pernambucana, Indústria e Comércio Através dos Impressos Litográficos Comerciais Recifenses (1930-1965). 2011. 224 f. Dissertação (Mestrado em Design) Universidade Federal de Pernambuco, UFPE, Brasil: 2011

ALI, Fátima. 2009. A Arte de Editar Revistas. São Paulo: Companhia Editora Nacional.

BARRETO CAMPELLO, S.; ARAGÃO, I. R. (Org.). Imagens comerciais de Pernambuco: ensaios sobre os efêmeros da Guaianases. 1. ed. Recife: Néctar, 2011. v. 1. 120p

Em busca da prática perdida. In: Silvio Barreto Campello; Isabella Aragão. (Org.). Imagens comerciais de Pernambuco: ensaios sobre os efêmeros da Guaianases. 1ed.Recife: Néctar, 2011, v. 1, p. 12-31. 
BARROS, H. de. Em busca da aura: dinâmicas de construção da imagem impressa para a simulação do original. 2008. 204 f. Dissertação (Mestrado) - Escola de Desenho Industrial, Universidade do Estado do Rio de Janeiro, Rio de Janeiro, 2008.

CANTERO, Francisco. Arte e técnica da imprensa moderna. São Paulo: Editora Jornal dos Livros, 1971

CARDOSO, Rafael. Uma introdução a História do Design, 3.ed. Rio de Janeiro: Editora Blucher, 2008. CAVALCANTE, Sebastião Antunes. O Design de Manoel Bandeira: Aspectos da Memória Gráfica de Pernambuco. 2012. 136 f. Dissertação (Mestrado em Design) Universidade Federal de Pernambuco, UFPE, Brasil: 2012

; BARRetO CAMPELLO, S. Ilustração e Artes Gráficas: Periódicos da Biblioteca Pública do Estado de Pernambuco \{1875 - 1939\}. 1. ed. São Paulo: Editora Edgard Blücher Ltda., 2014. v. 1. $114 p$.

CEPE - Companhia Editora de Pernambuco - Disponível em <https://www.cepe.com.br/index.php/cepe.html> Acesso: 11 de janeiro de 2018

CRAIG, James. Produção Gráfica. São Paulo: Mosaico: Ed. da Universidade de São Paulo, 1980.

CUNHA LIMA, Guilherme. 0 gráfico amador: as origens da moderna tipografia brasileira. Rio de Janeiro: Editora UFRJ, 1997

FERREIRA, Orlando da Costa. Imagem e letra. Introdução à bibliologia brasileira: a imagem gravada. São Paulo: Editora da Universidade de São Paulo, 1976.

FARIAS, Priscila Lena. On graphic memory as a strategy for design history. In: International Committee for Design History and Design Studies, Aveiro, Portugal, 2014.

FONSECA, Letícia Pedruzzi. Uma revolução gráfica Julião Machado e as revistas ilustradas no Brasil, 1895-1898. São Paulo: Editora Edgard Blücher Ltda, 2016

GASCOIGNE, Bane. How to Identify Prints, Second Edition. New York: Thames\&Hudson, 2004.

LIMA, Edna Lúcia Cunha. Cinco décadas de litografia comercial no Recife: Por uma história das marcas de cigarros registradas em Pernambuco, 1875-1924. Rio de Janeiro: Dissertação apresentada ao Departamento de Artes da PUC-RJ para obtenção do título de mestrado. 1998

MACÊDO, Ana Catarina. Propagandas em Revistas Recifenses das Décadas de 1910 a 1950. Recife: Fundação Joaquim Nabuco, 2009.

MARIZ, Leopoldina. Heinrich Moser: memória gráfica através das capas da Revista de Pernambuco. 2018. Dissertação (Mestrado em Design) Universidade Federal de Pernambuco, UFPE, Brasil: 2018

MEGGS, Philip B. História do Design Gráfico. São Paulo: Cosac\&Naify, 2009

NASCIMENTO, Luiz do. História da Imprensa de Pernambuco (1821-1954). Recife: Editora Universitária/UFPE, 1975.

PORTA, Frederico. Dicionário de Artes Gráficas. Rio de Janeiro: Editora Globo, 1958.

SOBRAL, Julieta Costa. J. Carlos Designer. In: Rafael Cardoso. (Org.). O Design Brasileiro antes do Design. 1 ed. São Paulo: Cosac\&Naify, 2005, p. 124-159. 